\title{
Effect of Magnesium Sulfate on the Total Anesthetic and Analgesic Requirements in Neurosurgery
}

\section{Essam M. Manaa ${ }^{1,2 *}$ and Amro F. Alhabib}

${ }^{1}$ Anesthesia Department, College of Medicine, Assiut University Hospital, Assiut, Egypt

${ }^{2}$ Anesthesia Department, College of Medicine, King Khalid University Hospital, King Saud University, Riyadh, Saudi Arabia

${ }^{3}$ Neurosurgery Department, King Khalid University Hospital, King Saud University, Riyadh, Saudi Arabia

\begin{abstract}
Background: Anesthesia for neurosurgery requires balancing deep and effective anesthesia as well as postoperative analgesia versus the risks of delayed recovery and postoperative respiratory depression. This randomized, placebo-controlled, double-blind study was designed to evaluate the effect of magnesium sulfate on the total anesthetic and analgesic consumption using the clinical parameters in addition to the bispectral index (BIS) and neuromuscular monitoring using train-of-four (TOF).
\end{abstract}

Patients and Methods: This study included 60 adult male and female patients, ASA physical status I and II, and undergoing neurosurgical procedures. Patients were randomly allocated into 2 equal groups. Patients in group I (magnesium group) received magnesium sulfate $(20 \mathrm{mg} / \mathrm{kg})$ as bolus dose over 5 minutes before induction of anesthesia, followed by $10 \mathrm{mg} / \mathrm{kg} / \mathrm{h}$ as infusion. While patients in group II (control group) received saline with the same bolus and infusion rates. All patients were induced by fentanyl $(2 \mu \mathrm{g} / \mathrm{kg})$, propofol $(1.5-2 \mathrm{mg} / \mathrm{kg})$ and rocuronium in a dose of $(0.6 \mathrm{mg} / \mathrm{kg})$ to facilitate tracheal intubation. This was followed by continuous infusion of propofol $(6-10$ $\mathrm{mg} / \mathrm{kg} / \mathrm{h})$ and fentanyl $(1-2 \mu \mathrm{g} / \mathrm{kg} / \mathrm{h})$.

Results: Results showed that total consumptions of fentanyl, propofol and rocuronium were significantly less $(P<0.05)$ in magnesium group when compared to control group. Recovery time was significantly shorter $(P<0.05)$ in magnesium group. Postoperative pain score as well as total analgesic requirement of morphine was significantly lower $(P<0.05)$ in magnesium group compared to control group.

Conclusion: Magnesium sulfate reduces the total anesthetic and analgesic requirements as well as postoperative pain.

Keywords: Magnesium sulfate; Neurosurgery; Anesthesia; Analgesia

\section{Introduction}

Magnesium is necessary for the presynaptic release of acetylcholine from nerve endings and may produce effects similar to calciumentry-blocking drugs [1]. With the discovery of the N-methylD-aspartate (NMDA) receptor and its links to nociceptive pain transmission and central sensitization, there has been renewed interest in utilizing noncompetitive NMDA receptor antagonists, as potential antihyperalgesic agents. The magnesium ion was the first agent discovered to be an NMDA channel blocker. At high doses, perioperative intravenous magnesium sulfate has been reported to reduce postoperative morphine consumption. Therefore, when magnesium sulfate is co-administered with propofol, it potentiates the anesthetic effect and NMDA antagonism of propofol [2].

Magnesium sulfate has vasodilator and hypotensive effect and therefore potentiates the hypotensive effect of propofol [3]. Magnesium sulfate also, has demonstrated a variety of neuroprotective actions in the central nervous system after induction of experimental ischemia and in clinical studies [4]. The CNS depressant effect of anesthetic agents may be potentiated when they are used concurrently with magnesium sulfate [5].

Previous studies have reported that preoperative administration of magnesium sulfate reduces intra- and post-operative analgesic requirements in patients undergoing knee surgery or abdominal hysterectomy [5]. However, most of those studies evaluated the analgesic and anesthetic requirements depending on clinical parameters mainly such as hemodynamics and pain score.

\section{Patients and Methods}

\section{Study groups}

This work had been carried out during the period from January 2009 to June 2011 after approval of the ethical committee (Ethical Committee $\mathrm{N}^{\circ}$ KKUH 106) of King Khalid University Hospital, King Saud University, Riyadh, Saudi Arabia on 10 December 2008. Written informed consents were obtained from all patients prior to entry into the study. The study included sixty adult male and female patients, ASA physical status I and II, with average weight and height, and undergoing neurosurgical procedures. Patients with significant organ dysfunctions (e.g. cardiac, respiratory, renal, or liver disorders), morbid obese or those on treatments with calcium channel blockers were excluded from the study.

All patients received oral lorazepam (1-2 mg) and ranitidine (150 $\mathrm{mg}$ ) as a premedication (1-2 hours) preoperatively. Before induction

*Corresponding author: Essam M. Manaa, Anesthesia Department, Assiut University Hospital, College of Medicine, Assiut, Egypt, Anesthesia Department (41), King Khalid University Hospital, King Saud University, Riyadh, Saudi Arabia, Tel: 00966509870124; Fax: 0096614692366; E-mail: e_manaa@yahoo.com

Received June 12, 2012; Accepted June 27, 2012; Published June 30, 2012

Citation: Manaa EM, Alhabib AF (2012)Effect of Magnesium Sulfate on the Total Anesthetic and Analgesic Requirements in Neurosurgery. J Neurol Neurophysiol S11-001. doi:10.4172/2155-9562.S11-001

Copyright: (c) 2012 Manaa EM, et al. This is an open-access article distributed under the terms of the Creative Commons Attribution License, which permits unrestricted use, distribution, and reproduction in any medium, provided the original author and source are credited. 
of anesthesia, patients in group (I) received the unknown solution (A), while patients in group (II) received the unknown solution (B) in a double blind fashion. The solutions were prepared in the pharmacy and the anesthetist was blinded to the grouping design. Patient in group (I) received magnesium sulfate $(20 \mathrm{mg} / \mathrm{kg})$ as bolus dose over 5 minutes before induction of anesthesia, followed by $(0.1 \mathrm{ml} / \mathrm{kg} / \mathrm{h})$ of $10 \%$ solution as continuous infusion. While patients in group (II) received saline with the same bolus and infusion rates, during the entire anesthesia period. Postoperative pain management was conducted by the acute pain team (APS) who was also blinded to the group assignment.

\section{Anesthetic technique}

As the patient was received in theatre, all the standard monitors were applied including $\mathrm{HR}$, arterial blood pressure, ECG, $\mathrm{Spo}_{2}, \mathrm{Etco}_{2}$ and temperature, in addition to neuromuscular monitoring 'TOF.' 'BIS' electrodes (BIS QUATRO - BX13366, Aspect Medical Systems, Inc. USA) were applied and connected to the monitoring system that was attached to the anesthesia machine (Zeus, Drager Medical \& Co.KG, 23542 Lubeck, Germany). After induction of anesthesia, arterial line was inserted for continuous monitoring of the blood pressure and frequent blood gas analysis.

Induction of anesthesia carried out with intravenous fentanyl (2 $\mu \mathrm{g} / \mathrm{kg})$, followed by propofol $(1.5-2 \mathrm{mg} / \mathrm{kg})$. Intubation was carried using rocuronium bromide in a dose of $(0.6 \mathrm{mg} / \mathrm{kg})$. Maintenance of anesthesia was carried by continuous infusion of propofol $(6-8 \mathrm{mg} / \mathrm{kg} / \mathrm{h}$ ) and was titrated to maintain the 'BIS' value within the range between (40-50) and fentanyl $(1-2 \mu \mathrm{g} / \mathrm{kg} / \mathrm{h})$ to maintain the hemodynamic parameters within $(20 \%)$ of the base line preoperative values. Muscle relaxation was monitored by 'TOF' every ten minutes, and when the 'TOF' stimulations were more than two responses, additional boluses of rocuronium $(0.2 \mathrm{mg} / \mathrm{kg})$ were administered. Lungs were mechanically ventilated to maintain normocapnia.

Baseline intravenous infusion rate of Lactated Ringer's solution was set at $6 \mathrm{ml} / \mathrm{kg} / \mathrm{h}$ in both groups. Additional solutions were infused if required. Infusion solutions were stopped as the surgeon started skin repair. At the end of the surgery, all anesthetics and solutions were withdrawn. The residual effect of rocuronium was reversed with neostigmine in a dose of $(0.05 \mathrm{mg} / \mathrm{kg})$ and glycopyrolate $(4 \mathrm{mg})$. Then the patient was extubated and transferred to either post anesthesia care unit 'PACU' or high dependency care unit 'HDU' for routine follow up. Every patient was observed continuously after the termination of anesthesia and times of events or any adverse events were recorded.

Pain was assessed by the VAS $(0-100 \mathrm{~mm})$ at immediate postoperative period till $48 \mathrm{~h}$ postoperative. Post operative pain relief was achieved by I.V morphine using patient controlled analgesia "PCA II Syringe Pump Product of Baxter Healthcare Corporation". The PCA machine was containing a dose of $50 \mathrm{mg}$ morphine in a total volume of $50 \mathrm{ml}$ saline $(1 \mathrm{mg} / \mathrm{mL}$ ). The machine set up was adjusted to deliver (1 $\mathrm{mg}$ ) bolus and the lockout interval was 10 minutes.

\section{Data for assessments} (MAP)

Heart Rate HR (beats/min) and Mean Arterial Blood Pressure

\section{Depth of anesthesia (BIS)}

Duration of anesthesia (by minutes): from the time of induction to withdrawal of all anesthetics.
The recovery time (by minutes): from withdrawal of all anesthetics to extubation.

Postoperative pain score by 'VAS' (0-100 mm).

Total anesthetic requirements during surgery.

Total postoperative analgesic requirements of morphine $(\mathrm{mg})$ during the $1^{\text {st }} 24$ hours.

\section{Statistical analysis}

Statistical analysis was done using "SPSS 19 for Windows" software. Data were collected from all patients during and after anesthesia. Descriptive statistics (mean, standard deviation "SD", and ranges) were calculated. Comparative statistics between the two groups were applied. Unpaired t-test was used to compare the mean values between the two groups. Mann-Whitney-U test was used to compare the difference between the two groups for non parametric variables (e.g. VAS). While, Chi-square test was used to compare the categorical variables between both groups (e.g. surgical diagnosis). Significant result was considered when $P$ value was less than (0.05).

\section{Results}

\section{Patient's characters}

Analysis of the results showed that there was no significant difference in patient characters between the two groups (Table 1).

\section{Anesthetic data}

Duration of anesthesia and recovery time: The duration of anesthesia showed no significant difference between the study groups $(\mathrm{P}>0.05)$. But the recovery time was significantly shorter in group I (magnesium group) compared to the control group $(\mathrm{P}<0.05)$ (Table 2).

\begin{tabular}{|l|c|c|}
\hline & Magnesium group $(\mathrm{n}=30)$ & Control group $(\mathrm{n}=30)$ \\
\hline $\begin{array}{l}\text { Age }(\mathrm{y}) \\
(\text { Mean } \pm \text { SD) } \\
\text { Range }\end{array}$ & $39.55 \pm 12.23$ & $35.50 \pm 9.06$ \\
\hline $\begin{array}{l}\text { Weight }(\mathrm{kg}) \\
(\text { Mean } \pm \mathrm{SD})\end{array}$ & $22-56$ & $22-50$ \\
\hline Range & $74.65 \pm 8.02$ & $72.50 \pm 7.97$ \\
\hline $\begin{array}{l}\text { Sex \# } \\
\text { (male/female) }\end{array}$ & $60-95$ & $65-90$ \\
\hline $\begin{array}{l}\text { Surgical diagnosis \# } \\
\text { - Craniotomy } \\
- \text { - Spine surgery }\end{array}$ & $19 / 11$ & $21 / 9$ \\
\hline
\end{tabular}

- Comparison between the two groups by unpaired t-test.

- (\#) Comparison by Chi square test.

- $\left(^{*}\right)$ Significant $(P<0.05)$

Table 1: Patients' characters.

\begin{tabular}{|l|c|c|}
\hline & Magnesium group $(\mathrm{n}=30)$ & Control group $(\mathrm{n}=30)$ \\
\hline $\begin{array}{l}\text { Age }(\mathrm{y}) \\
(\text { Mean } \pm \mathrm{SD})\end{array}$ & $197.50 \pm 45.158$ & $202.750 \pm 39.552$ \\
Range & $120-280$ & $135-270$ \\
\hline $\begin{array}{l}\text { Recovery time }(\mathrm{min}) \\
(\text { Mean } \pm \mathrm{SD})\end{array}$ & $6.96 \pm 0.673^{*}$ & $9.82 \pm 0.921$ \\
Range & $6-8$ & $8-12$ \\
\hline Propofol $(\mathrm{mg} / \mathrm{kg} / \mathrm{h})$ & $5.10 \pm 1.33^{*}$ & $6.29 \pm 1.67$ \\
\hline Fentanyl $(\mu \mathrm{g} / \mathrm{kg} / \mathrm{h})$ & $1.78 \pm 0.38^{*}$ & $2.57 \pm 0.51$ \\
\hline Rocuronium $(\mathrm{mg} / \mathrm{kg} / \mathrm{h})$ & $0.342 \pm 0.18^{*}$ & $0.491 \pm 0.07$ \\
\hline
\end{tabular}

- Comparison between the two groups by unpaired t-test.

- $\left({ }^{*}\right)$ Significant $(P<0.05)$

Table 2: Anesthetic data (Mean $\pm S D$ ). 
Citation: Manaa EM, Alhabib AF (2012)Effect of Magnesium Sulfate on the Total Anesthetic and Analgesic Requirements in Neurosurgery. J Neurol Neurophysiol S11-001. doi:10.4172/2155-9562.S11-001

Anesthetic agents consumption: The mean propofol consumption $(\mathrm{mg} / \mathrm{kg} / \mathrm{h})$ showed a statistically significant decrease $(\mathrm{P}<0.05)$ in magnesium group when compared to control group. The intraoperative fentanyl consumption was significantly less $(\mathrm{P}<0.05)$ in magnesium group compared with control group. Also the mean rocuronium requirement was significantly less in magnesium group $(\mathrm{P}<0.05)$ when compared to control group (Table 2).

\section{Vital signs}

Haemodynamics: The pre-operative mean values of HR and MAP $(\mathrm{mmHg})$ were comparable between the two groups $(\mathrm{P}>0.05)$. However after induction of anesthesia and thereafter, there was a significant reduction $(\mathrm{P}<0.05)$ in $\mathrm{HR}$ and MAP mean values in both groups when compared with the preoperative values (Figure 1 and 2).

BIS value: There was no significant difference $(\mathrm{P}>0.05)$ in the BIS mean values between the study groups starting from the preoperative period and throughout the anesthesia, till after extubation and recovery (Table 3).

\section{Postoperative pain managements}

Postoperative pain assessments by VAS (0-100 mm) showed significantly lower pain scores in magnesium group compared to

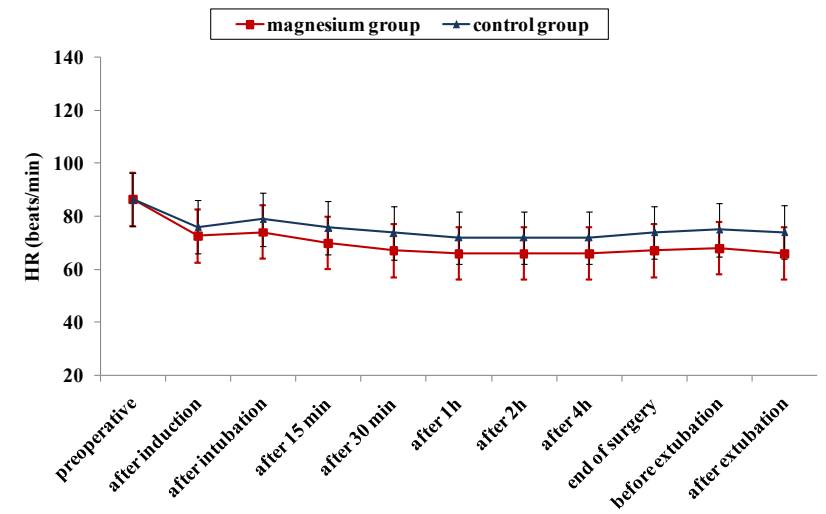

HR: Heart Rate

Figure 1: Mean heart rate values in both groups.

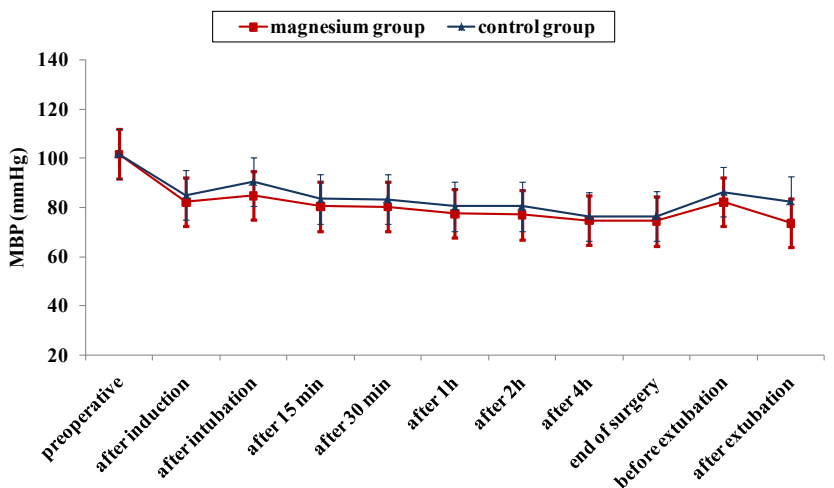

MBP: Mean Blood Pressure

Figure 2: Mean blood pressure values in both groups. control group (comparison by Whitney- $\mathrm{U}$ test revealed $\mathrm{P}<0.05$ ) (Figure $3)$.

As regard the postoperative pain relief, comparison between the two groups (by unpaired t-test) showed that there was a significant reduction $(\mathrm{P}<0.05)$ in the total cumulative doses of morphine consumption by PCA during the 1 st 24 hours in magnesium group compared to control group (Table 4).

\section{Discussion}

\section{Hemodynamics}

The present study indicates that magnesium sulfate reduced both the $\mathrm{HR} / \mathrm{min}$ and mean arterial blood pressure throughout the operative time. This was in agreement with many similar studies. Instead of fentanyl, Ryu et al. [6] used remifentanil with propofol as a part of total intravenous anesthesia in two groups of patients, one received magnesium sulfate and the other group received saline. Results showed that the mean MAP and HR were significantly reduced in magnesium

\begin{tabular}{|l|c|c|}
\hline & Magnesium group $(\mathrm{n}=30)$ & Control group $(\mathrm{n}=30)$ \\
\hline Before induction & $92.6 \pm 1.4$ & $93.4 \pm 1.2$ \\
\hline After induction & $54.85 \pm 2.6$ & $56.45 \pm 2.4$ \\
\hline After intubation & $41.55 \pm 2.4$ & $43.1 \pm 2.6$ \\
\hline Surgical stimulation & $42.3 \pm 2.2$ & $44.4 \pm 1.9$ \\
\hline Before extubation & $64.2 \pm 1.7$ & $66.4 \pm 1.4$ \\
\hline After extubation & $85.4 \pm 2.7$ & $88.5 \pm 1.9$ \\
\hline
\end{tabular}

Comparison between the two groups by unpaired t-test.

Table 3: 'BIS' values in both groups (Mean $\pm S D$ ).

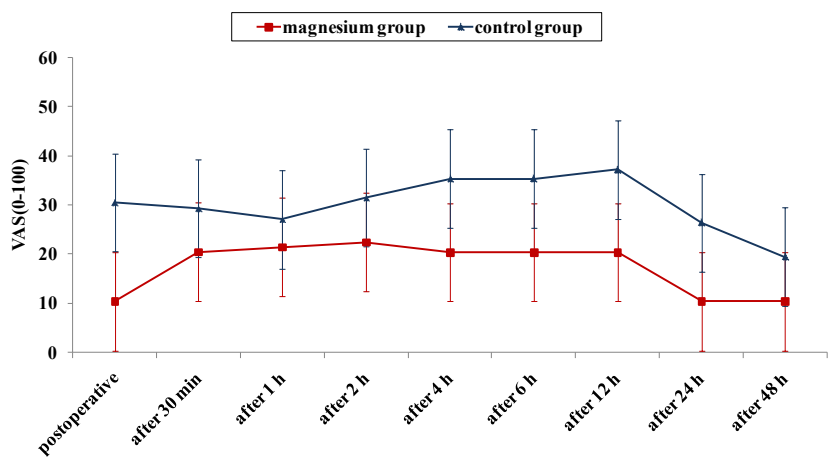

VAS: Visual Analog Scale

Figure 3: Mean visual analog scale values in both group.

\begin{tabular}{|l|c|c|}
\hline Morphine $(\mathrm{mg})$ & Magnesium group $(\mathrm{n}=30)$ & Control group $(\mathrm{n}=30)$ \\
\hline After 1 hour & $2.4 \pm 0.503^{*}$ & $5.1 \pm 0.641$ \\
\hline Range & $2-3$ & $2-6$ \\
\hline After 6 hours & $7.25 \pm 1.069^{*}$ & $10.5 \pm 1.418$ \\
Range & $6-9$ & $6-12$ \\
\hline After 12 hours & $10.5 \pm 0.887^{*}$ & $12.4 \pm 1.846$ \\
Range & $8-11$ & $10-15$ \\
\hline After 24 hours & $17.65 \pm 1.954^{*}$ & $23.35 \pm 2.30$ \\
\hline Range & $15-21$ & $20-28$ \\
\hline
\end{tabular}

- Comparison between the two groups by unpaired t-test.

- $\left({ }^{*}\right)$ Significant $(P<0.05)$.

Table 4: Post-operative morphine consumption by PCA (Mean \pm SD). 
group. While, Choi et al. [3] has maintained the hemodynamic parameters at the base line values by changing the propofol infusion rate when the MAP and HR changed and he concluded that the magnesium group required less propofol infusion than the other group. Also these results are in accordance with the results of Telci et al. [7] who adjusted the dose of the remifentanil and propofol according to the hemodynamic changes. Also, it has shown that magnesium decreased the systemic vascular resistance and attenuates the response to laryngoscopy and tracheal intubation [5].

\section{Anesthetic managements}

In anesthesia practice, the increases of blood pressure and heart rate are interpreted as the onset of pain and light anesthesia supposing that the other factors are stabilized [8].

There was a significant reduction in the infusion rates of propofol and fentanyl in magnesium group compared to the control group. It has been shown that, when $\mathrm{MgSO}_{4}$ is co-administered with propofol, it potentiates the anesthetic effect and NMDA antagonism of propofol. This result suggested that magnesium administration may be a useful adjunct to propofol anesthesia and this was associated with reduced propofol requirements $[3,6]$. Another mechanism could involve the reduction of catecholamine release through reduced sympathetic outflow and decrease the stress response to surgery [8]. This means that magnesium acts as part of balanced general anesthesia with propofol, fentanyl and mivacurium [9]. These results are in agreement with the result of Telci et al. [7] who has shown that the administration of magnesium led to significant reduction in the requirements for anesthetic drugs during total intravenous anesthesia (TIVA) with propofol, remifentanil and vecuronium. In another study, a bolus of $4 \mathrm{gm}$ magnesium resulted in a rapid but transient decrease in arterial blood pressure in hypertensive patients, whereas normotensive patients did not have any significant change in blood pressure [3]. Moreover, Tramer et al. [10] has shown that patients treated with magnesium did not show any significant hemodynamic difference compared with control patients in the intra-operative and post-operative period.

In the present study, I.V magnesium significantly reduced rocuronium consumption than the control group. This is in accordance with the similar studies that demonstrated significant reductions in vecuronium [7] or mivacurium [11] consumptions during TIVA with continuous magnesium administration.

The effect of vecuronium consumption is not surprising, as the effects of magnesium ions at the neuromuscular junction are well known [7]. The effects of magnesium on at the neuromuscular junction can be explained by the decreased release of acetylcholine at the motor nerve terminal, diminished depolarizing action of acetylcholine, and depressed excitability of the muscle fiber membrane, with the first effect being the most important [12]. Magnesium act competitively in blocking the entry of calcium in presynaptic endings. Presynaptic release of acetylcholine and its effects on the postsynaptic muscle receptors were reduced by magnesium [12].

Also, the duration of action of rocuronium was longer in the magnesium group than the control group and less frequent doses were needed. This prolonged action of the muscle relaxant was reported also in the presence of clindamycin and magnesium [13]. An interaction between magnesium sulfate and the none-depolarizing neuromuscular blocking agents (NMBAs) has been documented for many years. This was also observed in patients undergoing cardiac surgery, where administration of magnesium sulfate results in a (30-35 min) prolongation of the neuromuscular blockade induced with intubating and maintenance doses of cisatracurium [14].

In an attempt to speed up the onset of action of the NMBAs, magnesium has been given before pancuronium in one study [15], or before vecuronium and rocuronium in another study, in these settings the onset times were faster in the presence of magnesium [16].

The recovery time from anesthesia was significantly shorter in magnesium group compared to the control group. This was mainly attributed to the lower anesthetic consumptions in the magnesium group compared to the control group. This rapid recovery also reported by other studies in patients who received magnesium sulfate $[15,16]$. On the other hand Ray $\mathrm{M}$ et al. [9] showed that recovery time was significantly prolonged in patients receiving $\mathrm{MgSO} 4$ in comparison to other two groups that received clonidine or saline. They attributed the delay in recovery may be due to CNS depressant effect of $\mathrm{MgSO}_{4}$.

\section{Post operative analgesia}

Magnesium is a non-competitive (NMDA) receptor antagonist with antinociceptive effects. Magnesium sulfate has been previously investigated as a possible adjuvant for intra- and postoperative analgesia. The majority of these studies suggest that perioperative magnesium sulfate reduces anesthetic requirements and improves postoperative analgesia [6].

The present study showed a significant reduction in the total amount of morphine consumption by PCA used for postoperative pain relief as well as the postoperative pain scores in magnesium group compared to the control group. This is in agreement with other studies that showed perioperative magnesium sulfate was associated with smaller analgesic requirement, less discomfort and a better quality of sleep in the postoperative period [10]. While Ryu et al. [6] has shown that postoperative pain scores, cumulative analgesic consumption of morphine, and shivering incidents were significantly lower after intraoperative magnesium infusion. Other study has reported also that pre-operative administration of intravenous magnesium reduced the intra and post-operative analgesic requirements in patients undergoing orthopedic knee surgery or elective abdominal hysterectomy [5]. Also, magnesium could be adjuvant to peri-operative analgesics by lowering the fentanyl requirement $[2,17]$.

The uses of magnesium are not limited to the intra operative infusion only, but in the intensive care unit, magnesium sulfate infusion was associated with decreased sufentanil requirements. While Levaux et al. [18] has used magnesium sulfate as an adjuvant for postoperative analgesia after major lumbar surgery and they observed that the postoperative opioid consumption and pain scores were lower in the magnesium group than the control group. Also, Apan et al. [19] showed that postoperative magnesium sulfate infusion reduces analgesic requirements and prolongs the time to first analgesic request in patients undergoing spinal surgery under spinal anesthesia. Moreover magnesium sulfate administered before induction of anesthesia increases minimum alveolar anesthetic concentration of sevoflurane and reduces cardiovascular responses to intubation [20]. Therefore, it may be worthwhile use magnesium sulfate supplementation to intraoperative anesthetics and postoperative analgesia, since this molecule is inexpensive, relatively harmless, and the biological basis for its potential antinociceptive effect is promising [21].

\section{Limitations of this Study}

First, we used only one regimen of magnesium infusions, while 
Citation: Manaa EM, Alhabib AF (2012)Effect of Magnesium Sulfate on the Total Anesthetic and Analgesic Requirements in Neurosurgery. J Neurol Neurophysiol S11-001. doi:10.4172/2155-9562.S11-001

clinical studies showed that magnesium causes a dose-dependent negative inotropic effect [22]. Also, in another study, magnesium 40 $\mathrm{mg} / \mathrm{kg}$ bolus and $10 \mathrm{mg} / \mathrm{kg} / \mathrm{h}$ infusion regimen seems to fulfill clinical expectations of reducing the requirement for propofol and atracurium intraoperatively, and morphine after operation [23]. Second, the infusion was limited to intra operative period only. While some studies used magnesium infusion postoperatively after spinal anesthesia and showed a significant sedative effect with a reduction of the analgesic consumptions [19]. Third, we didn't measure the serum level of magnesium and assess the correlations between the magnesium level versus the total anesthetic and analgesic requirements. Lastly, we didn't evaluate the cost/effective analysis of this cheap medications compared to anesthetic medications. Schulz-Stübner et al. [11] showed that a 2-h anesthetic without magnesium would cost $21-35 \%$ more than in magnesium group.

\section{Conclusion}

From the previously mentioned data, we can conclude that magnesium sulfate is a safe and cost-effective supplement to a general anesthetic regimen with propofol, fentanyl and rocuronium as it reduces the total anesthetic requirements, post-operative pain score and post-operative analgesic requirements.

\section{Acknowledgement}

The author would like to acknowledge Dr. Salah N. Eltallawy, Associate Professor of Anesthesia and Dr. Abdulaziz E. Ahmad, Registrar of Anesthesia, King Khalid University Hospital, King Saud University, Riyadh, Saudi Arabia for their help throughout this study. No conflict of interest nor fund had been reported by them.

\section{References}

1. Marinov MB, Harbaugh KS, Hoopes PJ, Pikus HJ, Harbaugh RE (1996) Neuroprotective effects of preischemia intra-arterial magnesium sulfate in reversible focal cerebral ischemia. J Neurosurg 85: 117-124.

2. Buvanendran A, Kroin JS (2009) Multimodal analgesia for controlling acute postoperative pain. Curr Opin Anaesthesiol 22: 588-593.

3. Choi JC, Yoon KB, Um DJ, Kim C, Kim JS, et al. (2002) Intravenous magnesium sulfate administration reduces propofol infusion requirements during maintenance of propofol- $\mathrm{N}_{2} \mathrm{O}$ anesthesia: part $\mathrm{I}$ : comparing propofol requirements according to hemodynamic responses: part II: comparing bispectral index in control and magnesium groups.. Anesthesiology 97: 11371141.

4. Kaplan S, Ulus AT, Tutun U, Aksoyek A, Ozgencil E, et al. (2004) Effect of $\mathrm{Mg}_{2} \mathrm{SO}_{4}$ usage on spinal cord ischemia-reperfusion injury: electron microscopic and functional evaluation. Eur Surg Res 36: 20-25.

5. Koinig H, Wallner T, Marhofer $P$, Andel H, Hörauf K, et al. (1998) Magnesium sulfate reduces intra- and postoperative analgesic requirements. Anesth Analg 87: 206-210.

6. Ryu JH, Kang MH, Park KS, Do SH (2008) Effects of magnesium sulphate on intraoperative anaesthetic requirements and postoperative analgesia in gynaecology patients receiving total intravenous anaesthesia. $\mathrm{Br} J$ Anaesthesia 100: 397-403.

7. Telci L, Esen F, Akcora D, Erden T, Canbolat AT, et al. (2002) Evaluation of effects of magnesium sulphate in reducing intraoperative anaesthetic requirements. $\mathrm{Br} \mathrm{J}$ Anaesth 89: 594-598.

8. Gan TJ, Glass PS, Windsor A, Payne F, Rosow C, et al. (1997) Bispectra index monitoring allows faster emergence and improved recovery from propofol, alfentanil, and nitrous oxide anesthesia. BIS Utility Study Group. Anesthesiology 87: 808-815.

9. Ray M, Bhattacharjee DP, Hajra B, Pal R, Chatterjee N (2010) Effect of clonidine

This article was originally published in a special issue, Traumatic Brain Injury: Diagnosis \& Treatment handled by Editor(s). Dr. Douglas Mckay Wallace, University of Miami, USA and magnesium sulphate on anaesthetic consumption, haemodynamics and postoperative recovery: A comparative study. Indian J Anaesth 54: 137-141.

10. Tramer MR, Schneider J, Marti RA, Rifat K (1996) Role of magnesium sulfate in postoperative analgesia. Anesthesiology 84: 340-347.

11. Schulz-Stübner S, Wettmann G, Reyle-Hahn SM, Rossaint R (2001) Magnesium as part of balanced general anesthesia with propofol, remifentanil and mivacurium: a double-blind, randomized prospective study in 50 patients. Eur J Anaesthesiol 18: 723-729.

12. Saris NE, Mervaala E, Karppanen H, Khawaja JA, Lewenstam A (2000) Magnesium: an update on physiological, clinical and analytical aspects. Clinica Chimica Acta 294: 1-26.

13. Sloan PA, Rasul M (2002) Prolongation of pancuronium neuromuscular blockade by clindamycin and magnesium. Anesth Analg 94: 123-124.

14. Pinard AM, Donati F, Martineau R, Denault AY, Taillefer J, et al. (2003) Magnesium potentiates neuromuscular blockade with cisatracurium during cardiac surgery. Can J Anesth 50: 172-178.

15. James MF, Schenk PA, Van der Veen BW (1991) Priming of pancuronium with magnesium. Br J Anaesth 66: 247-249.

16. Kussman B, Shorten G, Uppington J, Comunale ME (1997) Administration of magnesium sulfate before rocuronium: effects on speed of onset and duration of neuromuscular block. Br J Anaesth 79: 122-124.

17. Mandal PK (2003) Isoflurane anaesthesia for functional endoscopic sinus surgery. Indian J Anesth 47: 37-40.

18. Levaux Ch, Bonhomme V, Dewandre PY, Brichant JF, Hans P (2003) Effect of intra-operative magnesium sulphate on pain relief and patient comfort after major lumbar orthopedic surgery. Anesthesia 58: 131-135.

19. Apan A, Buyukkocak U, Ozcan S, Sari F, Basar H (2004) Postoperative magnesium sulphate infusion reduces analgesic requirements in spinal anaesthesia. Eur J Anaesthesiol 21: 766-769.

20. Durmus M, But AK, Erdem TB, Ozpolat Z, Ersoy MO (2006) The effects of magnesium sulphate on sevoflurane minimum alveolar concentrations and haemodynamic responses. Eur J Anaesthesiol 23: 54-59.

21. Lee C, Jang MS, Song YK, Seri O, Moon SY, et al. (2008) The effect of magnesium sulfate on postoperative pain in patients undergoing major abdominal surgery under remifentanil-based anesthesia. Korean J Anesthesio 55: 286-290.

22. Hwang JY, Na HS, Jeon YT, Ro Y, Kim CS, Do SH (2010) I.V infusion of magnesium sulphate during spinal anaesthesia improves postoperative analgesia. Br J Anaesth 104: 89-93.

23. Seyhan TO, Tugrul M, Sungur MO, Kayacan S, Telci L, et al. (2006) Effects of three different dose regimens of magnesium on propofol requirements, haemodynamic variables and postoperative pain relief in gynaecological surgery. Br J Anaesth 96: 247-252. 